\title{
High Frequency of TGF- $\beta$-Receptor-II Mutations in Microdissected Tissue Samples from Laryngeal Squamous Cell Carcinomas
}

\author{
Andreas G. Nerlich, Ulrich Sauer, Isabell Ruoss, and Hjalmar G. Hagedorn \\ Institute of Pathology (AGN), Academic Hospital München-Bogenhausen, and Institute of Pathology (US, IR) and \\ Department of ENT-Diseases (HGH), Ludwig-Maximilians-University, Munich, Germany
}

\begin{abstract}
SUMMARY: In this study we analyze 105 paraformaldehyde-fixed and paraffin-embedded tumor samples from 12 patients with invasive squamous cell carcinoma of the larynx for the presence of gene mutations of the complete TGF- $\beta$-receptor-II (TBR-II) gene. This study was conducted on tissue samples following separation of tumor cell groups from adjacent stroma cell compartments by laser microdissection, resulting in pure tumor cell complexes of approximately 50 to 500 cells. We detected 35 different mutations in 5 of the 12 patients analyzed but none in numerous samples of the normal peritumoral stroma or in normal epithelium. Twelve of the mutations were silent and nonfunctional, whereas the 23 relevant mutations were either bp replacements leading to amino acid exchanges or deletions leading to frame shifts and premature stop codons. Except for the so-called "big polyadenine tract" in exon 3 with several similar mutations, no further mutational hot spot was found. In addition we found a correlation between mutations and a loss of typical TGF- $\beta$ effects in tumor cells (high cell proliferation rate) but not in the stroma cells (low proliferative capacity, significant de novo deposition of matrix material). This study is the first to identify a high mutational rate of the TBR-II gene in laryngeal squamous cell carcinoma. We show that that only small tumor-cell groups are affected. The molecular abnormalities are variable, and only one hot spot of mutations can be identified (exon 3 , big polyadenine tract). These defects and possibly comparable mutations in other proteins of the TGF- $\beta$-signaling cascade seem to be associated with enhanced cell proliferation rates and alterations of the peritumoral matrix. (Lab Invest 2003, 83:1241-1251).
\end{abstract}

$A$ Ithough the natural history of malignant neoplasms seems to be controlled by a multitude of factors, an increasing body of evidence suggests that the inactivation of tumor suppressor genes is the driving force behind the growth of most neoplasms (Kelly and Rizzino, 1999). This is derived from the observation that several malignant tumor types show an inactivation of tumor suppressor genes. For example, in colorectal cancer the loss of function of well known tumor suppressor genes, such as APC, DCP4/ smad4, and $p 53$, has been observed at high frequency (Gryfe et al, 1997; Kinzler and Vogelstein, 1996).

The various isoforms of TGF- $\beta$ and their receptors represent a unique system that is involved in the mediation of significant cell functions, such as cell growth and differentiation, morphogenesis, and the remodeling of connective tissues (Piek et al, 1999). In particular, it has been shown that TGF- $\beta$ s are among the most potent inhibitors of cell proliferation (Chu et al, 1999; de Castecker et al, 2000; Kelly and Rizzino,

DOI: 10.1097/01.LAB.0000081389.98880.79

Received May 22, 2003.

This study was supported by a grant from Wilhelm-Sander-Stiftung (No. 9501702).

Address reprint requests to: Dr. Andreas G. Nerlich, Institute of Pathology, Academic Hospital Munich-Bogenhausen, Englschalkingerstrasse 77, D-81925 Munich, Germany. E-mail: Andreas.Nerlich@extern. lrz-muenchen.de
1999). In most malignant neoplasms, the control of cellular proliferation is lost; therefore, a widely accepted concept suggests that a critical step of carcinogenesis is the deregulation of TGF- $\beta$ action and its signaling function. Because the TGF- $\beta$ signal is mediated by specific cell-surface receptors, the TBRs, the focus is now on these receptor proteins. There exist three receptor proteins, of which TBR-II is the primary linkage site for the various TGF- $\beta$ s. Following ligand binding to TBR-II, this protein links to TBR-I. The complex formation initiates phosphokinase activity and thus intracytoplasmic signaling. TBR-III, also known as betaglycan, enhances binding of TGF- $\beta 2$ to TBR-II and -I (de Castecker et al, 2000; Kelly and Rizzino, 1999; Piek et al, 1999).

Currently it is assumed that the TGF- $\beta$ receptors act as very potent tumor suppressors by controlling the cellular proliferation cascade and that the molecular disturbance of these receptors may lead to carcinogenesis (de Castecker et al, 2000; Kelly and Rizzino, 1999). Mutations have particularly been identified in TBR-Il (Lu et al, 1995; Parsons et al, 1995). Thus, tumor cell lines showing genomic instability (RER $+/-$ phenotype) show mutations to considerable amount in this receptor protein. Likewise, $71 \%$ to $90 \%$ of those colorectal carcinomas and $71 \%$ of gastric carcinomas and gliomas reveal gross structural mutations mainly affecting a 10-bp poly-A tract in the encoding region of exon 3 (Izumoto et al, 1997; Park et al, 1994). However, in a few studies TBR-II mutations have also 
been detected in gastric carcinomas that lack the microsatellite instability (de Castecker et al, 2000), and two inactivating point mutations have been detected in head and neck squamous cell carcinoma (SCC) (Garrigue-Antar et al, 1995; Izumoto et al, 1997). Recently, Chen et al (2001) showed a high number of TBR-II mutations in microdissected ovarian carcinoma. In addition there exist a number of reports indicating that various neoplasms, including gastric cancer cell lines (de Castecker et al, 2000), thyroid tumors (Garrigue-Antar et al, 1995; Lazzereschi et al, 1997), and small-cell lung carcinomas (de Jonge et al, 1997; Lazzereschi et al,1997), show either reduced or even missing expression of the TBR-/l gene, but do not have apparent structural mutations in the coding region of the gene. In addition other tumor types, such as SCCs of the uterine cervix, also did not show TBR-II mutations, although these were occasionally detected in closely related cell lines (Chu et al, 1999).

Despite the previous reports on TBR-II mutations, there is a discrepancy between the yet few mutations identified in several tumors and the high frequency of tumors with disturbance of the cell proliferation. In particular, no study exists to date that determines the frequency of mutations in the TBR-Il gene in an unselected group of malignant tumors. We, therefore, used a well-defined study population of laryngeal SCCs and used laser microdissection to selectively analyze the tumor cells in small compartments of the tumor tissue in comparison to nontumoral epithelia and stroma cells. Using this approach we were able to identify a significant number of various mutations in the TBR-Il gene, which are, however, restricted to small tumor-cell groups. A correlation to typical TGF- $\beta$ effects and their potential failure indicates that the mutations may have direct impact on the loss of TGF- $\beta$ effects, although this does not fully explain the observed cellular abnormalities. From our observations we deduce that TBR-II mutations occur frequently in small tumor-cell groups and that this could play a significant role in tumor progression.

\section{Results}

In the present study, a total of 105 samples of isolated tumor cell groups were analyzed. These were investigated in two sets of subsequently performed experiments.

From 12 different patients, 60 tumor samples (five from each patient) were analyzed in the first set of experiments. Further, 45 tumor samples were obtained from three of those patients (with yet identified mutations in the TBR-II gene) from various areas within the tumor. These tumor samples were compared with 24 samples of normal epithelium and 24 samples of peritumoral stroma (two from each patient), which served as controls.

All 153 samples analyzed from tumor, normal epithelium, and stroma were subjected to DNA extraction, PCR amplification of exons 1 to 7 of the TBR-II gene, and single-stranded conformation polymorphism (SSCP) analysis of the amplicons. In parallel, numerous blanks served as negative controls, which were included in the various analyses.

\section{DNA Extraction and Amplification}

Due to technical reasons (failure of DNA extraction or amplification), isolated analyses had to be excluded from this study. The major reasons were assumed to be (a) a too small amount of tumor cells removed, (b) DNA alteration during fixation and embedding of the tumor specimens, or (c) inhibition of PCR amplification due to the presence of inhibiting substances. Thus, for the analysis of exon 1, we had to exclude two of the tumor samples (out of 105), for exon 2 five samples, for exon 3 ten tumor samples, for exon 4 four samples, for exon 5 two samples, for exon 6 seven samples, and for exon 7 five samples.

\section{SSCP Analysis}

For all PCR products, SSCP gel electrophoresis was performed, resulting in the typical two-band pattern for the two separated DNA single strands. In the first set of experiments, artificial mutations by insertion of only one single-base mismatch into the PCR primers had been produced (see "Materials and Methods" section), which resulted in a significant alteration of the migration pattern (Fig. 2A).

A

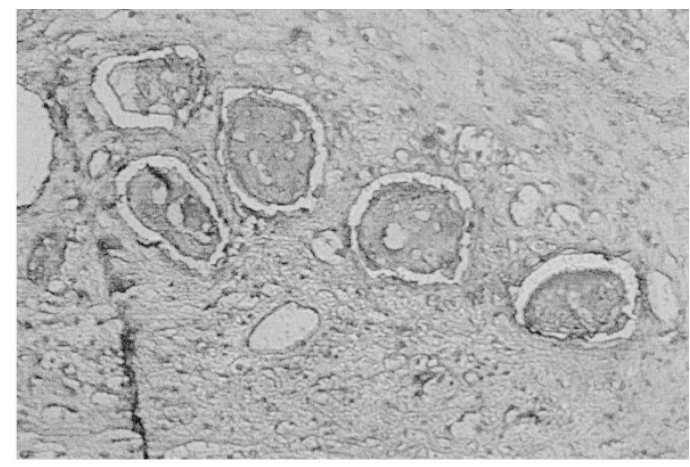

B

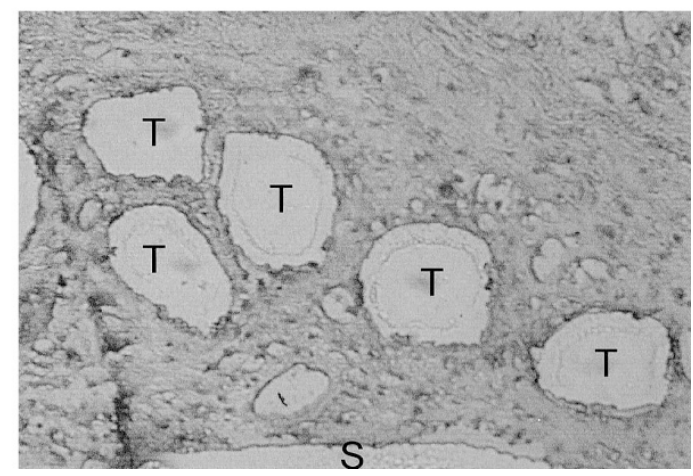

Figure 1.

Histology of the microdissected tissue samples. (A) Before the removal of the tumor or stroma cell areas, these regions are outlined by the laser beam. Note that samples of pure cell populations were obtained. (B) Following the catapult removal of the samples into collecting vials, the empty spaces of tumor $(T)$ and stroma $(S)$ areas are clearly visible. (Fast red staining, mounted without cover slips; original magnification, $\times 400$.) 


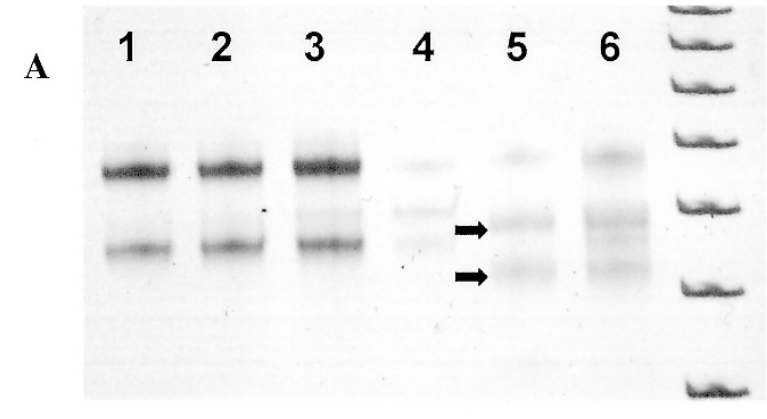

B

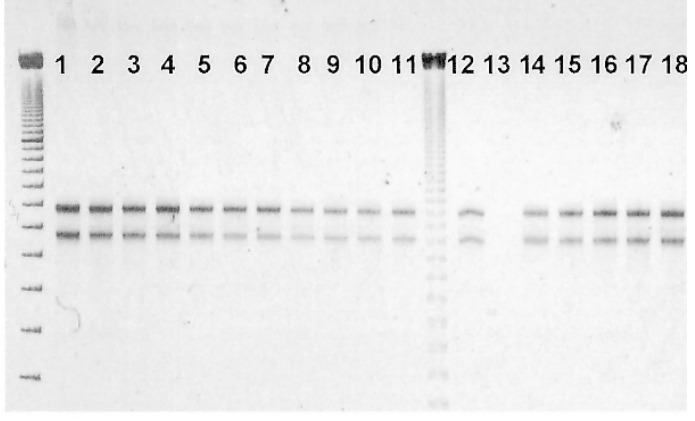

C

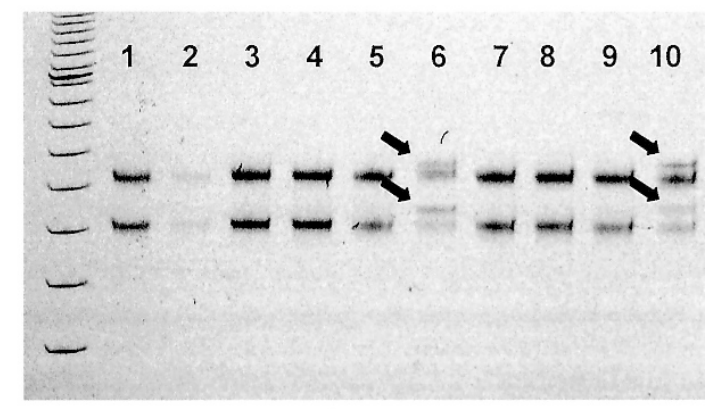

D

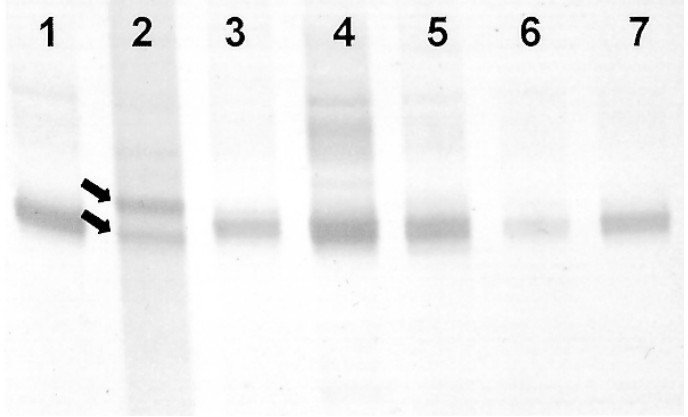

Figure 2.

Results of the single-stranded conformation polymorphism (SSCP) analysis. (A) In the first set of experiments, artificial mutations were induced during the amplification process. Although a normal banding pattern is seen in the controls using normal primers (Lanes 1 to 4 ), the exclusive application of primers introducing mutation (Lane 5 ) results in only shifted bands (arrows). The application of both mutated and normal primers shows both normal and abnormal bands (Lane 6, exon 5). (B) SSCP gel showing the amplification products of a series of samples for exon 5 . Here, no abnormal banding pattern is seen. $(C)$ In a further set of samples, the amplification product of exon 5 reveals an abnormal banding pattern in two cases (Lanes 6 and 10), with the typical occurrence of additional bands (arrows). (D) One sample (Lane 2) shows exclusively two abnormally running bands (arrows). Note that in this gel the two regular SSCP bands are running close together.

Of the 24 samples of normal epithelium and those from peritumoral stromal samples, additional bands were seen in SSCPS of one or several exons in only seven samples. None of the normal tissues showed exclusively abnormally migrating bands. In contrast, besides cases with normal banding pattern (Fig. 2B), tumor samples revealed in 52 of the 105 samples abnormally migrating SSCP bands as exclusively abnormal bands or as at least additional bands in one or several exons. In most instances additional atypically migrating bands were seen together with regular bands (Fig. 2C), whereas the exclusively present abnormal bands were seen in only few isolated cases (Fig. 2D). While these migration abnormalities in the SSCP analysis were seen in 52 tumor samples, several of the samples had multiple banding abnormalities affecting different exons. Thus, an abnormal and additional banding pattern had to be recorded in 19 samples in exon 1, 27 samples in exon 2, 23 samples in exon 3, 18 samples in exon 4, 12 samples in exon 5, 26 samples in exon 6, and 19 samples in exon 7.

A comparison of the localization of the cells corresponding to abnormally migrating samples within the tumor tissue revealed a clearly higher rate of SSCP abnormalities derived from areas located at the tumor periphery, such as the invasion front (between 55\% and $80 \%$ of abnormal bands), than in the tumor center (between 20\% and 45\%).

\section{Identification of TBR-II Mutations}

To identify relevant mutations, all abnormally or additionally migrating bands of the SSCP gels were excised and sequenced. A total of 203 samples were excised from normal and tumor tissues and sequenced. Out of these analyses, 35 different mutations of the TBR-I/ gene could be identified in a total of 30 amplicons (Table 3 and Fig. 3).

In the first set of experiments when a total of 60 tumor samples of 12 patients had been analyzed 12 different mutations in the tumor samples of five individuals had been noted. In the 45 samples obtained from three of these five individuals with yet proven mutations, 23 mutations were recorded. All mutations were widely distributed over the whole TBR-Il genome except for exons 1 and 6, in which we were not able to identify any mutation despite several cases with apparent SSCP abnormality. In exon 3, four samples presented two different mutations each; in exon 7 one sample showed two different mutations simultaneously.

The only hot spot of mutation was the poly-A region in exon 3 (codons 126 to 128) (Markowitz et al, 1995), where we observed four samples with loss of an adenine causing a $(-1)$ frame shift. Most other mutations were bp replacements resulting in an exchange of amino acids. However, in 12 samples with overt mutation, this did not lead to a change in the amino acid sequence (silent mutations). Taking these nonrelevant silent mutations into account, the rate of TBR-II mutations identified in this study comprised 23 relevant instances $(21.9 \%$ of samples and $41.7 \%$ of individuals analyzed).

In all of the samples of normal epithelium and those from peritumoral stroma, which showed additional bands in SSCPs of one or several exons, no mutation 
Table 1. Patient Group and Clinical Data

\begin{tabular}{rcccccccc}
\hline No. & Age & Sex & $\begin{array}{c}\text { Tumor } \\
\text { location }\end{array}$ & $\begin{array}{c}\text { Tumor } \\
\text { stage }^{a}\end{array}$ & $\begin{array}{c}\text { Lymph } \\
\text { node } \\
\text { metastases }^{a}\end{array}$ & $\begin{array}{c}\text { Hematogenous } \\
\text { metastases }^{b}\end{array}$ & $\begin{array}{c}\text { Tumor } \\
\text { recurrence }\end{array}$ & $\begin{array}{c}\text { Interval } \\
\text { (months) }^{c}\end{array}$ \\
\hline 1 & 85 & F & G $^{+}$ & pT4 & pN0 & M0 & + & 24 \\
2 & 50 & M & Supra-G & pT4 & pN1 & M0 & + & 12 \\
3 & 56 & M & G & pT4 & pN2c & M1 & - & - \\
4 & 58 & M & G & pT4 & pN0 & M1 & - & - \\
5 & 59 & F & Supra-G & pT3 & pN2b & M0 & - & - \\
6 & 50 & M & G & pT3 & pN0 & M0 & - & - \\
7 & 86 & M & E & PT2 & pN0 & M0 & + & - \\
8 & 71 & M & E & pT3 & pN0 & M0 & - & - \\
9 & 62 & M & Sub-G & pT4 & pN0 & M0 & - & - \\
10 & 54 & M & Supra-G & pT4 & pN2b & M1 & + & 10 \\
11 & 66 & M & G & pT4 & pN2b & M0 & + & 5 \\
12 & 53 & M & G & pT3 & pN0 & M0 & - & - \\
\hline
\end{tabular}

E, extensive tumor growth; $G$, glottic tumor.

${ }^{a}$ Tumor stage and lymph node status were determined postoperatively.

${ }^{b}$ Hematogenous metastases were detected by clinical examination.

${ }^{c}$ Time interval between primary tumor treatment and tumor recurrence.

could be observed. All mutations we found were exclusively in tumor samples. Five mutations could also be confirmed by re-amplification of the tumor DNA and re-performing the molecular analysis.

Finally, in all samples analyzed (ie, the normal epithelium, the stroma samples, and the tumor samples), we identified a sequence difference when compared with the published sequence. Therefore, the alanine in position 439 could be shown to always be replaced by a valine in our sequences. This indicates a polymorphism without obvious pathologic consequences. The obvious polymorphism will be provided to gene data banks.

\section{Morphology and Immunohistochemical Characteristics of Microdissected Tumor Cell Groups with Overt TBR-II Mutation}

The separation of tumor cells from the surrounding peritumoral stroma resulted in cell groups of between 50 and 500 cells (Fig. 1). Part of the samples covered cell nests growing as small cell groups surrounded by peritumoral stroma (tumor front); further samples were removed from the center of larger tumor areas (tumor center). The tumor cell groups with proven mutation were morphologically indistinguishable from adjacent tumor cell groups without mutation. In particular, we did not observe major differences in the degree of tumor cell differentiation between both conditions.

Because cell proliferation is under strict control of TGF- $\beta$, we tried to correlate the tumor cell proliferation rate (as evidenced by the presence of the $\mathrm{Ki}-67$ antigen) and the presence of TBR-II mutations (Fig. $4 \mathrm{~A})$. In general the tumor cell proliferation rate was more enhanced at the tumor periphery than in the tumor center. This was consistent with the majority of areas of proven mutation. However, a statistical comparison of the cell proliferation rate of mutated cell groups (Ki-67-labeled tumor cells: $14.4 \% \pm 5.6 \%$ ) with those without mutation $(12.2 \% \pm 6.7 \%)$ provided no significant difference. In addition there was no evidence for significantly enhanced proliferation rate of the peritumoral stroma cells.

A correlation between the deposition of extracellular matrix (newly formed matrix, as revealed by collagen type III and tenascin) (Fig. 4B) and TBR-II mutations did not provide any statistically relevant association, as was the presence of TGF- $\beta 1,-\beta 2$, or $-\beta 3$ not related to the TBR-II mutations. In addition the presence of TBR proteins for all three TBRs tested did not provide an obvious loss of TBR protein in those areas where mutations could be identified on the molecular level (data not shown).

\section{Discussion}

The TGF- $\beta$ signaling pathway and its disturbance is assumed to play an important role in carcinogenesis (de Castecker et al, 2000; Kelly and Rizzino, 1999). Thereby, the tumor cells often escape from the strong antiproliferative effect of TGF- $\beta$ by mutational inactivation or dysregulation of components of its signaling pathway, such as the TGF- $\beta$ receptors and the intracellular signaling proteins, the Smads. Previous studies have confirmed this concept by showing mutations of the two major TGF- $\beta$ receptors, TBR-I and $-\mathrm{II}$, and several Smads, including the Smad-4 protein (Chen et al, 2001; Kelly and Rizzino, 1999). In particular, several mutations identified in the TBR-II gene have led to the opinion that this receptor protein may be a main target of mutations. However, in a recent review on this subject, Kim and colleagues (2000) compiled only 12 yet identified mutations in the biggest part of this receptor's gene and several uncounted mutations of the 10-bp polyadenine tract (the so-called "big polyadenine tract") in exon 3. The latter gene region seems to be a particular target for mutations. In general these authors claim that TBR-II mutations other than those affecting the big polyadenine tract of exon 3 are rare 

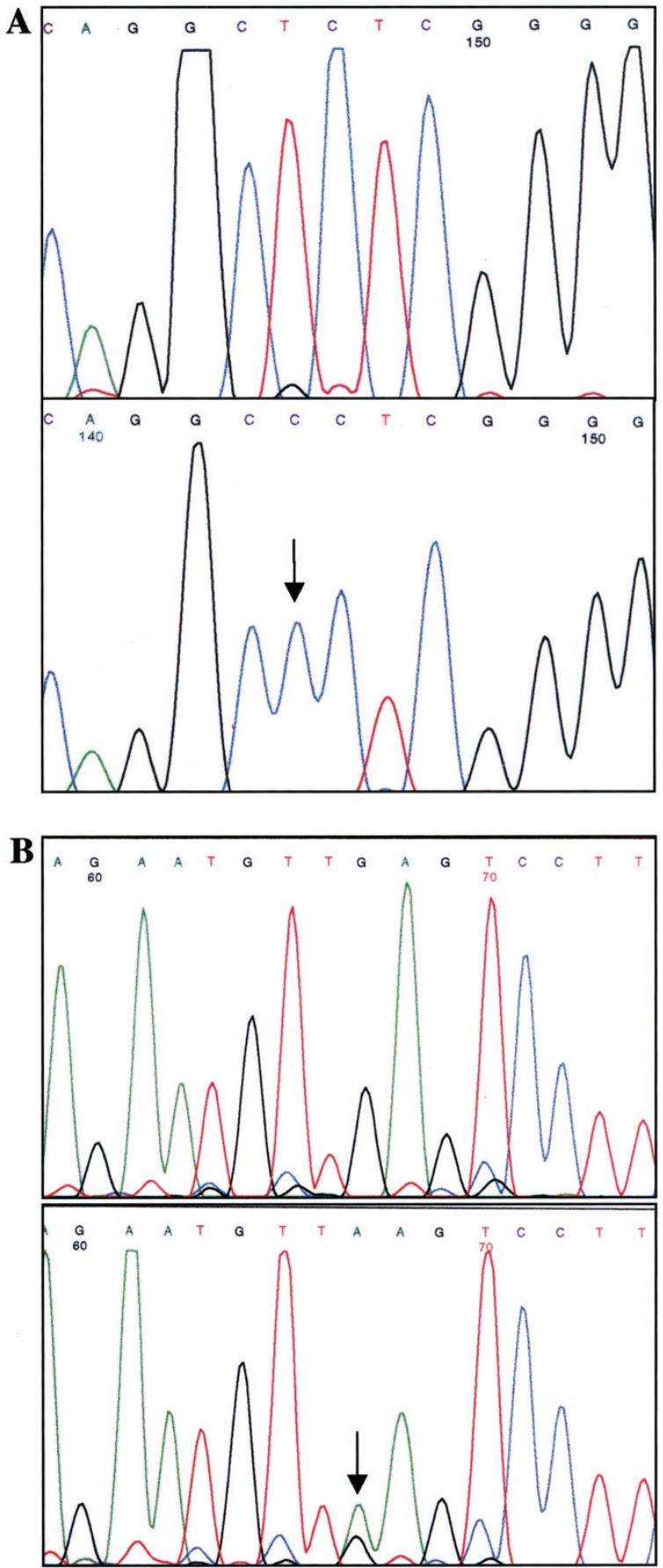

Figure 3.

Sequence data of mutations. (A) The sequence comparison between the normal (upper) and mutated sequence (lower) clearly shows the base exchange of $\mathrm{T}$ to $\mathrm{C}$ in exon 7, resulting in an amino acid exchange from Leu to Pro (Patient 1). (B) A sequence comparison between the normal (upper) and mutated sequence (lower) reveals a base exchange of $G$ to $A$ in exon 5 , resulting in an amino acid exchange from Glu to Lys (Patient 4).

events in tumorigenesis. They suggest that a prevalent mechanism by which tumor cells lose TGF- $\beta$ sensitivity is through transcriptional repression of TGF- $\beta$ receptor expression.

In the present study, we provide clear evidence in a small series of individuals suffering from SCC of the larynx that mutations of the TBR-II gene occur much more frequently when the analyzed tissue samples are selected by a small island of tumor cells. These observations may impede a novel approach to intratumoral genetic abnormalities of tumor suppressor genes, as well as to mutational heterogeneity, and may provide a novel concept as to the resulting effects on the growth pattern of those tumors. This may also easily explain the lack of detection of mutations in larger tissues samples that do not distinguish between pure-tumor and stroma-cell compartments (Chu et al, 1999; Myeroff et al, 1995).

In our study we used laser microdissected tumor samples to increase the amount of tumor DNA for analysis. This eliminates the contribution of any nontumoral DNA (eg, resulting from normal epithelium of the specimen's surface or the large nontumoral stroma cell compartment) to the analytic procedure. The unexpected high number of mutations in the $T B R-/ l$ gene in our study clearly supports the notion that the analysis of nondissected tissue samples may easily be influenced by the bulk of nontumor tissue, thereby reducing the chance to detect and identify mutations occurring in small tumor-cell groups.

Using this microdissection approach, we observed in the first set of experiments one or several mutations of the TBR-Il gene in one or several of the samples that had been randomly removed from 5 of the 12 individuals. Despite extensive parallel analysis, no mutations were seen in both the normal epithelium adjacent to the tumor area or in the peritumoral stroma cells. Therefore, we provide clear evidence that the removal of only a very limited amount of microdissected tumor material (five samples from each tumor) already resulted in the identification of mutations in almost half of our patient population (41.7\%).

In the second set of analyses, we extended the search for mutations on microdissected tumor tissue samples to find out the frequency of those mutations when more samples were removed. In this set of experiments, 15 samples were removed and analyzed from each of three patients with yet identified mutations. In this additional series, 23 mutations could be identified. This clearly highlights the unexpected high frequency of mutations in the TBR-Il gene. Although part of those mutations presented as silent mutations $(n=12)$, we identified relevant mutations in more than $20 \%$ of our sample group. It seems fair to assume that the analysis of further samples would have significantly increased the detected mutation rate. It also seems fair to speculate that each tumor would have shown TBR-Il mutations, provided that enough samples were analyzed.

Most interestingly the observed mutations were almost randomly distributed over the TBR-II genome, except for exons 1 and 6 (no mutation shown despite several SSCP abnormalities) and exon 3 (four mutations in the big polyadenine tract), which has already been mentioned to show enhanced mutational activity (de Castecker et al, 2000; Kim et al, 2000). The fact that we also found an increased mutational activity in this hot spot may further indicate that the observed mutations in this study are not due to technical prob- 

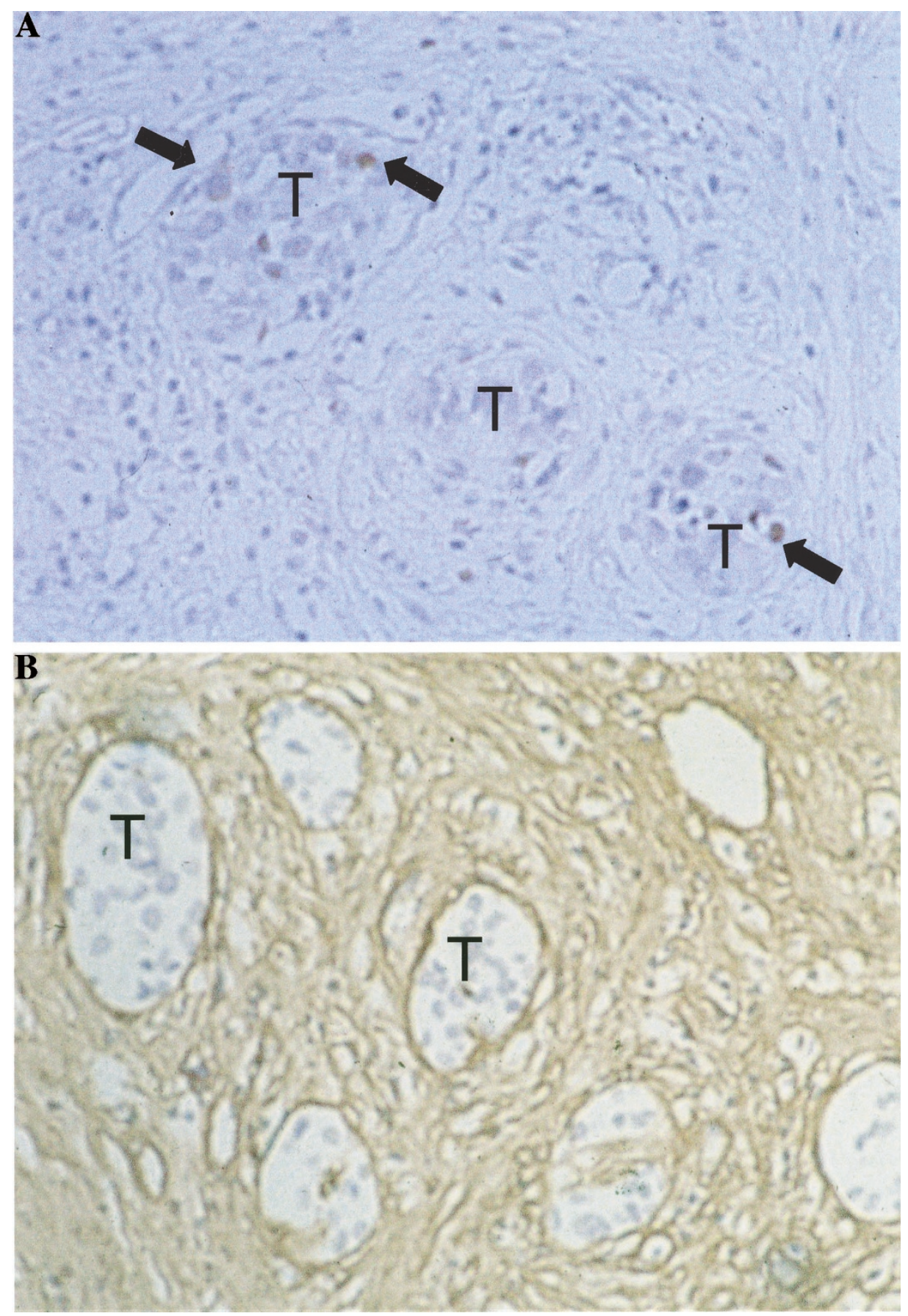

\section{Figure 4.}

Immunohistochemical findings. (A) The immunodetection of proliferating cells (by Ki-67 antigen staining) reveals positive staining in several tumor cells (arrows) within the tumor nests. (B) The immunolocalization of tenascin shows an extensive peritumoral staining indicating significant new formation of matrix material close to the tumor nests $(T)$. Original magnification, $\times 400$.

lems. This observation also provides clear evidence that the mutations affecting the TBR-II gene seem to be more randomly distributed during the process of carcinogenesis than thought before (de Castecker et al, 2000; Kim et al, 2000).

One might criticize the fact that the analytical approach of our study may be insufficient with regard to a possible influence of the laser manipulation on the genome and the specificity and sensitivity of our screening technique, the SSCP analysis. First, exten- sive previous studies by others provide clear evidence that the laser microdissection does not alter the genome (Becker et al, 1996). Furthermore, all tissue samples from normal epithelium and stroma did not reveal mutations despite their removal by the same laser microdissection procedure as the tumor samples. Secondly, the efficiency to identify mutations by SSCP analysis was tested prior to the study of patient material by inserting artificial mutations into amplicons according to the method described by Ruiz et al 
Table 2. Primer Pairs for Molecular Analysis ${ }^{a}$

\begin{tabular}{|c|c|c|c|c|c|}
\hline Exon & Upper primer & Lower primer & $\begin{array}{c}\text { Annealing } \\
\text { temperature } \\
\left({ }^{\circ} \mathrm{C}\right)\end{array}$ & $\begin{array}{l}\text { Product } \\
\text { size } \\
\text { (bp) }\end{array}$ & $\begin{array}{l}\text { Exon } \\
\text { size } \\
\text { (bp) }\end{array}$ \\
\hline 1 & 5'-CAT CTG GCC CGC ACA TCT-3' & 5'-CGG GCT GGG GAC CAC TC-3' & 62 & 248 & 94 \\
\hline 2 & 5'-CTG GCA GTT GGA TAA TCA TT-3' & 5'-GGG GAA AAG AAA GAA TAA CTT-3' & 60 & 252 & 169 \\
\hline 3 & 5'-CCC TCG CTT CCA ATG AAT CTC-3' & 5'-CCC ACA CCC TTT AGA GAA GAA-3' & 60 & 250 & 191 \\
\hline $4 A^{b}$ & 5'-CAA СТC СТT СТС TCC TTG TT-3' & 5'-GCA GCT CTG TGT TGT GG-3' & 55 & 305 & \\
\hline $4 \mathrm{~B}^{b}$ & 5'-TCC ACG TGT GCC AAC-3' & 5'-TGC CGC GTC AGG TA-3' & 58 & 335 & 800 \\
\hline $4 C^{b}$ & 5'-CCT TCC ACG CCA AG-3' & 5'-TCA AGG TAA AGG GGA TCT-3' & 58 & 315 & \\
\hline $5 A^{c}$ & 5'-AGG GGC CAC CAT CAG-3' & 5'-TAA CCC CTG GAA TAA TGC TC-3' & 64 & 311 & \\
\hline $5 \mathrm{~B}^{c}$ & 5'-GGC CTC ACT GTC TGT TTT TG-3' & 5'-TAC ACA TAT CTG GTC CAC ACC T-3' & 64 & 192 & 142 \\
\hline 6 & 5'-ACA TGC CAT TCT CAG TGA C-3' & 5'-GAA TTC TCT GCC ACC TAA GA-3' & 55 & 241 & 128 \\
\hline 7 & 5'-GCG GAC CCA CCA ACT CAT-3' & 5'-CCA GCC TGC CCC ATA AGA-3' & 55 & 248 & 180 \\
\hline
\end{tabular}

(1997). These control experiments clearly showed that those molecular modifications resulted in major alterations of the banding pattern. It is not surprising that the frequency of abnormal or additional SSCP bands clearly exceeded that of proven (silent and relevant) mutations. The seven samples of normal epithelium that showed an additional banding pattern in SSCP did not contain mutations. Therefore, it is fair to assume that even minor alterations, eg, in the folding of an otherwise regular DNA, may result in an abnormal SSCP banding pattern.

Finally, we tested whether those tumor cell areas with mutations revealed morphologic features that might distinguish them from nonmutated tumor cells. Adjacent (semi-serial) sections were morphologically analyzed by routine morphology and immunohistochemistry for TGF- $\beta$ isoforms and the TBRs, but also for parameters that might show typical TGF- $\beta$ effects, such as control of the cell proliferation and de novo formation of extracellular matrix material (Hagedorn et al, 1999; Piek et al, 1999). Likewise, in another study tumor cells of laryngeal SCC showed a significantly enhanced proliferation rate (as evidenced by increased Ki-67 index), which affected the tumor periphery (invasion front) more than the tumor center (Hagedorn et al, 1998). Also the de novo formation of certain matrix molecules, most presumably by the nonmutated stroma cells, has been described by the enhanced deposition of collagen type III and tenascin (Hagedorn et al, 1999). This has also been seen in the current study population. In addition we did not observe routine morphologic differences between mutation and nonmutation areas, such as variances in the degree of tumor cell differentiation, or significant differences in immunohistochemically detectable parameters. This holds particularly true for the expression of the Ki-67 antigen as a parameter for cellular proliferation. Thus, mutation areas showed enhanced cell proliferation rates, but elevated proliferation rates were not restricted to those mutation regions. Although this observation might be influenced by artificial factors (eg, the mutation bearing tumor cells might not have been included in the adjacent semi-serial sections), we suggest that mutations affecting other factors (eg, the Smads) might be effective as well. In general, however, we concluded that at least part of the enhanced proliferative activity of the tumor cells is associated with TBR-II mutations. Similar observations are described by Park et al (2002) for lung cancer. They found an increased proliferation rate for tumor cell lines obtaining a TBR-II mutation. Finally, we have no evidence for a loss of the TBR-Il protein in those mutation areas. This is well in line with a previous study that showed that all three TBRs are only slightly and nonsignificantly reduced in laryngeal carcinomas (Hagedorn et al, 2001). Previous assumptions by others that the TBR proteins are partially (Muro-Cacho et al, 1999) or even completely lost (Eisma et al, 1996) could not be confirmed.

There exist only very few previous studies that deal with mutation analyses of SCCs. Paterson et al, (2001) found mutations for TBR-II in oral SCC lines, and in a report of tumors of the uterine cervix, Chu et al (1999) also found TBR-II gene mutations in cancer cell lines but not in the tumor tissue. The possible reason, therefore, has been discussed above. A similar mechanism may be effective at explaining the lack of mutation identification in a study by Hori et al (1996) on esophageal SCCs. Ku et al (1999) discovered in two out of six human laryngeal SCC cell lines, the presence of relevant TBR-II mutations and in further two cell lines, found silent mutations. In light of our observations, these findings may now be explained by a possible selection mechanism of the mutated cells during establishing of cultures. However, they support our notion that the TBR-II gene mutation may be frequent in those tumor types.

In summary this study presents a novel pathobiologic concept of TBR-II in the carcinogenesis of SCCs. We propose that TBR-II mutations are much more frequent than previously supposed and, together with possible other targets of the TGF- $\beta$ signaling cascade, that they may lead to enhanced cell proliferation. These local mutations seem to affect tumor cells and cell groups of not more than 50 to 500 cells, and we 
Table 3. Mutations in TBR-II in the Study Material

\begin{tabular}{|c|c|c|c|c|}
\hline Patient $^{a}$ & Exon & Codon & Genomic DNA & Amino acid \\
\hline 1 & 2 & 35 & $\mathrm{Gac}>\mathrm{GTC}$ & Asp $>$ Val \\
\hline 1 & 2 & 39 & $\mathrm{ACT}>\mathrm{ACC}$ & Silent mutation (Thr) \\
\hline 1 & 2 & 82 & $\mathrm{GAA}>\mathrm{GAG}$ & Silent mutation (Glu) \\
\hline 3 & 3 & $96+94$ & $\mathrm{ACA}>\mathrm{ATA}+\mathrm{AAC}>\mathrm{GAC}$ & Thr $>$ Ile + Asn $>$ Asp \\
\hline 1 & 3 & $96+-1 \mathrm{~A} \mathrm{BPT} b$ & $\mathrm{ACA}>\mathrm{ACG}+$ & Silent mutation $(\mathrm{Thr})+$ Frame Shift \\
\hline 1 & 3 & $102+-1 \mathrm{~A} \mathrm{BPT}^{b}$ & $\mathrm{CAT}>\mathrm{CAC}$ & Silent mutation $(\mathrm{His})+$ Frame Shift \\
\hline 1 & 3 & 136 & $\mathrm{TGT}>\mathrm{CGT}$ & Cys $>$ Arg \\
\hline 1 & 3 & $142+-1 \mathrm{~A} \mathrm{BPT}^{b}$ & $\mathrm{GAG}>\mathrm{GGG}$ & Glu $>$ Gly + Frame Shift \\
\hline 4 & 3 & $-1 \mathrm{~A} \mathrm{BPT}^{b}$ & & Frame Shift \\
\hline 7 & 4 & 179 & $\mathrm{GCC}>\mathrm{GAC}$ & Ala $>$ Asp \\
\hline 1 & 4 & 199 & TCA $>$ TAA & Ser $>$ Stop \\
\hline 7 & 4 & 254 & $\mathrm{CGC}>\mathrm{CAC}$ & $\operatorname{Arg}>\mathrm{His}$ \\
\hline 7 & 4 & 260 & $A A G>A C G$ & Lys $>$ Thr \\
\hline 4 & 4 & 279 & $\mathrm{TTT}>\mathrm{TTC}$ & Silent mutation (Phe) \\
\hline 7 & 4 & 282 & $\mathrm{GAG}>\mathrm{GAT}$ & Glu $>$ Asp \\
\hline 3 & 4 & 379 & $\mathrm{GAC}>\mathrm{GTC}$ & Asp $>$ Val \\
\hline 3 & 5 & 420 & $\mathrm{GGA}>\mathrm{GGG}$ & Silent mutation (Gly) \\
\hline 3 & 5 & 426 & $\mathrm{GCT}>\mathrm{GCC}$ & Silent mutation (Ala) \\
\hline 3 & 5 & 433 & $A G G>G G G$ & Arg $>$ Gly \\
\hline 4 & 5 & 440 & $\mathrm{GAG}>\mathrm{AAG}$ & Glu $>$ Lys \\
\hline 3 & 5 & 441 & $\mathrm{TCC}>\mathrm{CCC}$ & Ser $>$ Pro \\
\hline 3 & 5 & 441 & $\mathrm{TCC}>\mathrm{TCT}$ & Silent mutation (Ser) \\
\hline 4 & 5 & 449 & $\mathrm{TCC}>\mathrm{CCC}$ & Ser $>$ Pro \\
\hline 11 & 5 & 463 & $\mathrm{GCA}>\mathrm{GCG}$ & Silent mutation (Ala) \\
\hline 4 & 7 & 513 & GTG $>$ GUG & Silent mutation (Val) \\
\hline 3 & 7 & 520 & TGC $>$ GGC & Cys $>$ Gly \\
\hline 4 & 7 & $522+-1$ G 533 & $\mathrm{GAC}>\mathrm{GAT}$ & Silent mutation (Asp) + frame shift \\
\hline 1 & 7 & 530 & $\mathrm{ACA}>\mathrm{GCA}$ & Thr $>$ Ala \\
\hline 1 & 7 & 547 & $\mathrm{CTC}>\mathrm{CCC}$ & Leu $>$ Pro \\
\hline 4 & 7 & 549 & $\mathrm{GGG}>\mathrm{GGA}$ & Silent mutation (Gly) \\
\hline
\end{tabular}

BPT, big polyadenin tract.

${ }^{a}$ Ranking according to the gene sequence.

${ }^{b}$ Codon 126 to 128; see Markowitz et al, 1995.

hypothesize that they may represent a growth advantage to those cell groups leading to foci of growth. Thus, we speculate that those mutated tumor cell foci may significantly contribute to the overall growth properties of those tumors. Finally, it seems fair to assume that this hypothesis might be effective much more generally in other types of malignant tumors representing a basic principle of tumor progression. This concept, however, awaits confirmation by experimental tests of other tumors and tumor types.

\section{Materials and Methods}

\section{Study Population}

The present study was conducted on tissue samples from 12 individuals with histologically verified laryngeal SCC (10 men and 2 women)(Table 1). The age ranged between 50 and 86 years. In all cases the tumor material had been obtained by primary surgical resection without prior chemo- or radiotherapy. In six cases the tumor was restricted to the glottic area, three cases were supraglottic, one was localized subglottically, and two tumors extended beyond the larynx. Five tumors had lymph node metastases, and in three cases distant hematogenous metastases were recorded. Within an observation period of between 35 and 48 months after the tumor removal, five patients suffered from recurrent disease. Detailed patient information is given in Table 1.

\section{Tissue Preparation}

From each patient tissue samples were fixed in 4\% paraformaldehyde and embedded into paraffin wax according to routine protocols. These blocks were used for the preparation of hematoxylin and eosinstained $4-\mu \mathrm{m}$-thick tissue sections for routine histopathologic examination. Subsequent sections were stained only with nuclear fast red, remained without cover slips, and were deparaffinized prior to microdissection. In addition further sections were used for the immunolocalization of cell proliferation marker, matrix deposition, and TGF- $\beta$ signaling as described below.

\section{Immunohistochemistry}

The immunolocalization of proliferating cells (mAb MIB-1 recognizing the Ki-67 antigen; DAKO, Hamburg, Germany); tenascin (DAKO); collagen type III (Dr. E. 
Schleicher, Tübingen University, Germany) as newly deposited extracellular matrix material; TGF- $\beta-1,-2$, and-3; and TBR-I, -II, and -III (all antibodies from Santa Cruz, Inc., Santa Cruz, California) was performed as described previously (Hagedorn et al, 1999; Norgaard et al, 1996) using the indicated commercially available antibodies. Appropriate tissue sections were deparaffinized in xylene and descending concentrations of alcohol and enzymatically pretreated as previously described (Hagedorn et al, 1999; Norgaard et al, 1996). Following incubation with the respective monospecific primary antibodies and washing steps, the antigen-antibody complex was detected by a secondary antibody system coupled either with the avidin-biotin system (ABC-complex method, Vector, Burlingame, California) (Hagedorn et al, 2001) or the APAAP system (DAKO) (Hsu et al, 1981). The reaction product was subsequently visualized by chromogene substances (diaminobenzidine and fast red, respectively; Sigma Chemicals, Deisenhofen, Germany).

\section{UV-Laser Microdissection}

To separate tumor cells from the surrounding, intermingled non-neoplastic stroma and stromal cells, we used a UV-laser microdissection strategy (PALM, Bernried, Germany) (Fig. 1). For this procedure, appropriate $2-\mu \mathrm{m}$ tissue slices were mounted on a $6-\mu \mathrm{m}$ thin supporting membrane, stained with nuclear fast red, but remained without cover slips as described previously (Cordell et al, 1984). From these sections small pure-cell groups of tumor or stromal cells and normal epithelium were cut out using a motorized computer controlled microscope (allowing object positioning and sample collection with nanometer precision) and a small nitrogen laser of high beam quality, which is coupled through a fluorescence illumination path with the microscope. The track of the UV laser microbeam dissects the membrane with the attached tissue along the edge of the interesting area, allowing it to exactly respond to the irregular feature of the histologic section and to cut out even small cell groups or single cells. Then the probe is catapulted by the laser into a collecting PCR tube (Fig. 1). As previously shown, laser irradiation does not affect the genetic information of the prepared cells (Böhm et al, 1993).

\section{Sample Selection and Study Design}

For further analysis the material was prepared using a dual approach. In the first set of analyses, five samples each comprising exclusively tumor cell groups were obtained from all 12 patients. The samples were attributed to the growth zone of the tumor, ie, it was recorded whether the material was from the tumor periphery or from central tumor zones. Additionally, from each section two samples were removed from the peritumoral stroma and two samples were obtained from normal epithelium that was seen on the specimen surface. All tissue samples tumor, stroma, and the normal epithelium were treated the same way for further DNA extraction and PCR analysis.

In the second set of analyses, 15 samples of tumor cell groups were removed from three of the aforementioned cases with already-proven mutations of the TBR-Il gene (see below) with random distribution. These samples were processed identically to those of the first set.

\section{DNA Extraction and PCR Analysis}

The collected samples were processed for extraction and amplification of DNA using a commercial kit (QIAamp DNA Mini Kit; Qiagen, Hilden, Germany). They were incubated with a buffer (ASL) containing 15 $\mu$ l proteinase $\mathrm{K}$ at $55^{\circ} \mathrm{C}$ for 24 hours. Then the samples were heated at $95^{\circ} \mathrm{C}$ for 10 minutes to inactivate the proteinase $\mathrm{K}$. The material was washed (buffer $A L$ ) and incubated with ethanol. Following binding (QIAmp spin column) and washings (buffers AW1 and AW2) the DNA-containing eluate was used for PCR amplification using specific primers for the different exons of TBR-II. Nine PCR primer pairs covering all seven exons of the TBR-Il gene were designed using the OLIGO program (Oligo 6.22; MedProbe, Oslo, Norway) and synthesized by commercial source (Interactiva, Ulm, Germany). The respective gene sequences had been selected according to published sequence data (GenBank accession numbers U-52240 through U-52246 and U-69146 through U-69152) (Table 2 ). Most exons comprise gene segments of 100 to $200 \mathrm{bp}$ so that the respective exon could be amplified in one step. For exon 4, however, which has a length of approximately $800 \mathrm{bp}$, three different primer pairs amplifying overlapping sequences were selected. For exon 5 a nested PCR protocol was used to obtain sufficient specific products. In general the PCR amplification was performed according to tested protocols (Sambrook and Russell, 2000). Detailed data on the primers and the PCR conditions are presented in Table 2.

To rule out artificial Taq or other PCR enzymeinduced mutations, we performed parallel experiments with different enzymes, and in all cases identical mutations could be identified. In addition we also used a proofreading enzyme (Pwo-polymerase; Roche Diagnostics, Mannheim, Germany) to confirm the mutation in five samples.

\section{SSCP Analysis}

For the screening analysis of mutations, SSCP analysis of the amplified fragments was performed according to routine protocols (Amersham Pharmacia Biotech, application notes). The amplified DNA was separated by nondenaturing polyacrylamide gel electrophoresis, and the resulting bands were visualized with silver staining. Mobility deviations of the two single strands were recorded, and the respective bands were cut out. The removed gel fragments were placed into sterile tubes with $50 \mu \mathrm{l} 10 \mathrm{~mm}$ Tris- $\mathrm{HCl}, \mathrm{pH}$ 9.0, $50 \mathrm{~mm} \mathrm{KCl}, 1.5 \mathrm{~mm} \mathrm{MgCl}$, and $0.1 \%$ Triton 
X-100, and were boiled for 20 minutes at $95^{\circ}$ C. A 4- $\mu$ l aliquot was used for specific PCR amplification using the same primer pairs and conditions as in the initial amplification step as mentioned above (Table 2).

Following this re-amplification, a preparative $1 \%$ agarose gel was run, and the resulting specific bands were cut out. The material was then transferred into Ultrafree DA tubes (Millipore, Bedford, United Kingdom) and centrifuged for 10 minutes at $5000 \times g$ to extract the DNA. A 100- $\mu$ l aliquot of the eluate and 400 $\mu$ distilled water were transferred to PCR centrifugal filter devices (Micron), centrifuged for 15 minutes at $1000 \times g$ and the filtrate discarded. For the elution of the DNA, $20 \mu$ l of distilled water was added, and the devices inverted and centrifuged for 2 minutes at $1000 \times g$.

To test the sensitivity of the SSCP reaction, artificial mutations of the amplified DNA were produced as described previously (Ruiz et al, 1997). Briefly, single bp exchanges were introduced through PCR primers containing single mismatches in a small 3 '-elongated sequence ( +5 bases), compared with the regular primers.

\section{Sequencing of the DNA}

Isolated DNAs from bands with abnormal migration pattern in SSCP were subjected to cycle sequencing using an automated sequencer (ABI 310; Perkin Elmer, Weiterstadt, Germany). For the sequencing $4 \mu \mathrm{l}$ of the resulting Microcon-eluate (see above) were mixed with $4 \mu \mathrm{l}$ DNA sequencing mix (Dye terminator cycle sequencing kit, PE Biosystems, Warington, United Kingdom) and $1 \mu \mathrm{l}$ water was added together with $1 \mu \mathrm{l}$ of the respective primer. Following cycle sequencing the material was purified with a Dye Ex spin kit (Qiagen, Hilden, Germany) and centrifuged for 3 minutes at $3000 \times g$. The $10-\mu$ l eluate was then vacuum dried. Subsequently, $12 \mu \mathrm{l}$ Template Suppression Reagent (Perkin Elmer, Weiterstadt, Germany) were added, boiled for 4 minutes at $95^{\circ} \mathrm{C}$, cooled in an ice bath, and transferred to the sequencer.

\section{Validation of Mutations}

To further rule out artificial mutations, we used five DNA probes of tumor tissue with mutation in the TBR-II gene and started the analysis again at the PCR level. In all five cases, we were able to identify the same mutation in the control analysis.

\section{References}

Becker I, Becker KF, Röhrl MH, Minkus G, Schütze K, and Höfler H (1996). Single-cell mutation analysis of tumors from stained histologic slides. Lab Invest 75:801-807.

Böhm M, Wieland I, and Totzeck B (1993). Detection of tumor-specific homozygous deletions in human biopsies by polymerase chain reaction. Cancer Gent Cytogenet 65:8387.

Chen T, Triplett J, Dehner B, Hust B, Colligan B, Pemberton J, Graff J, and Carter J (2001). Transforming growth factor- $\beta$ receptor type I gene is frequently mutated in ovarian carcinomas. Cancer Res 16:4679-4682.
Chu TY, Lai JS, Shen CY, Lio HS, and Chao CF (1999). Frequent aberration of the transforming growth factor- $\beta$ receptor II gene in cell lines but no apparent mutation in pre-invasive and invasive carcinomas of the uterine cervix. Int J Cancer 80:506-510.

Cordell JL, Falini B, Erber WN, Ghosh AK, Abdulaziz Z, MacDonald S, Pulford KA, Stein H, and Mason DY (1984). Immunoenzymatic labeling of monoclonal antibodies using immune complexes of alkaline phosphatase and monoclonal anti-alkaline phosphatase (APAAP complexes). J Histochem Cytochem 32:219-229.

de Castecker MP, Piek E, and Roberts AB (2000). Role of transforming growth factor- $\beta$ signaling in cancer. J Natl Inst Cancer 92:1388-1402.

de Jonge RR, Garrigue-Antar L, Vellucci VF, and Reiss M (1997). Frequent inactivation of the transforming growth factor $\beta$ type II receptor in small-cell lung carcinoma cells. Oncology Res 9:89-98.

Eisma RJ, Spiro JD, von Biberstein SE, Lindquist R, and Kreutzer DL (1996). Decreased expression of transforming growth factor beta receptors on head and neck squamous cell carcinoma tumor cells. Am J Surg 101:641-645.

Garrigue-Antar L, Munoz-Antonia T, Antonia SJ, Gesmonde $\mathrm{J}$, Vellucci VF, and Reiss M (1995). Missense mutations of the transforming growth factor beta type II receptor in human head and neck squamous carcinoma cells. Cancer Res 55:3982-3987.

Gryfe R, Swallow C, Banat B, Redston M, Gallinger S, and Couture J (1997). Molecular biology of colorectal cancer. Curr Probl Cancer 21:233-300.

Hagedorn H, Elbertzhagen A, Ruoss I, Sauer U, and Nerlich A (2001). Immunohistochemical analysis of major TGF- $\beta$ isoforms and their receptors in laryngeal carcinomas. Virchows Arch Pathol 439:531-539.

Hagedorn H, Sauer U, Schleicher E, and Nerlich AG (1999). Expression of TGF-beta 1 protein and mRNA and the effect on the tissue remodeling in laryngeal carcinomas. Anticancer Res 19:4265-4272.

Hagedorn H, Tübel J, Wiest I, and Nerlich AG (1998). In situ apoptotic and proliferation index in laryngeal squamous cell carcinomas. Anal Cell Pathol 16:177-184.

Hori H, Miyake S, Akiyama Y, Endo M, and Yuasa Y (1996). Clonal heterogeneity of human esophageal squamous cell carcinomas on DNA analysis. Jpn J Cancer Res 87:923-929.

Hsu SM, Raine L, and Fanger H (1981). A comparative study of the peroxidase-antiperoxidase method and an avidinbiotin complex method for studying polypeptide hormones with radioimmunoassay antibodies. Am J Clin Pathol 75: $734-739$

Izumoto S, Arita N, Ohnishi T, Hiraga S, Taki T, Tomita N, Ohue M, and Hayakawa T (1997). Microstallite instability and mutated type II transforming growth factor-beta receptor gene in gliomas. Cancer Lett 112:251-256.

Kelly DL and Rizzino A (1999). Growth regulatory factors and carcinogenesis: The roles played by transforming growth factor $\beta$, its receptors and signaling pathways. Anticancer Res 19:4791-4808.

Kim SJ, Im YH, Markowitz SD, and Bang YJ (2000). Molecular mechanisms of inactivation of TGF-beta receptors during carcinogenesis. Cytokine Growth Factor Rev 11:159-168. 
Kinzler KW and Vogelstein B (1996). Lessons from hereditary colorectal cancer. Cell 87:159-170.

$\mathrm{Ku} J \mathrm{~L}$, Kim WH, Lee JH, Park HS, Kim KH, Sung MW, and Park JG (1999). Establishment and characterization of human laryngeal squamous cell carcinoma cell lines. Laryngoscope 109:976-982.

Lazzereschi D, Ranieri A, Mincione G, Taccogna S, Nardi F, and Colletta G (1997). Human malignant thyroid tumors displayed reduced levels of transforming growth factor beta receptor type II messenger RNA and protein. Cancer Res 57:2071-2076.

Lu SL, Zhang WC, Akiyama Y, Nomizu T, and Yuasa Y (1995). Genomic structure of the transforming growth factor $\beta$ type II receptor gene and its mutations in hereditary nonpolyposis colorectal cancers. Cancer Res 56:4595-4598.

Markowitz S, Wand J, Myeroff L, Parsons R, Sun L, Lutterbaugh J, Fan RS, Zborowska E, Kinzler KW, Vogelstein B, et al (1995). Inactivation of the type II TGF-beta receptor in colon cancer cells with microsatellite instability. Science 268:1336-1338.

Muro-Cacho CA, Anderson M, Cordero J, and MunozAntonia T (1999). Expression of transforming growth factor $\beta$ type II receptors in head and neck squamous cell carcinoma. Clin Cancer Res 5:1243-1248.

Myeroff LL, Parsons R, Kim SJ, Hedrick L, Cho KR, Orth K, Mathis M, Kinzler KW, Lutterbaugh J, Park K, et al (1995). A transforming growth factor $\beta$ receptor type II gene mutation common in colon and gastric but rare in endometrial cancers with microsatellite instability. Cancer Res 55:5545-5547.

Norgaard P, Spang-Thomsen M, and Poulsen HS (1996). Expression and autoregulation of transforming growth factor beta receptor mRNA in small-cell lung cancer cell lines. $\mathrm{Br} \mathrm{J}$ Cancer 73:1037-1043.
Park C, Kim WS, Choi Y, Kim H, and Park K (2002). Effects of transforming growth factor (TGF-) receptor on lung carcinogenesis. Lung Cancer 38:143-147.

Park K, Kim SJ, Bang YJ, Park JG, Roberts AB, and Sporn MB (1994). Genetic changes in the transforming growth factor $\beta$ (TGF- $\beta$ ) type II receptor gene in human gastric cancer cells: Correlation with sensitivity to growth inhibition by TGF- $\beta$. Proc Natl Acad Sci USA 91:8772-8776.

Parsons R, Myeroff LL, Liu B, Wilson JK, Markowitz SD, Kinzler KW, and Vogelstein B (1995). Microsatellite instability and mutations of the transforming growth factor beta type II receptor gene in colorectal cancer. Cancer Res 55:55485550.

Paterson I, Matthews J, Huntley S, Robinson M, Fahey M, Parkinson K, and Prime S (2001). Decreased expression of TGF- $\beta$ cell surface receptors during progression of human oral squamous cell carcinoma. J Pathol 193:458-467.

Piek E, Heldin CH, and Ten Dike P (1999). Specificity, diversity and regulation in TGF- $\beta$ superfamily signaling. FASEB J 13:2105-2124.

Ruiz A, Antinolo G, Borrego S, Sanchez B, and Sanchez J (1997). PCR mutagenesis-based method for generation of positive controls for SSCP analysis. BioTechniques 23:704708.

Sambrook J and Russell D (2000). Molecular Cloning: A Laboratory Manual, 3rd ed., Cold Spring Harbor: Cold Spring Harbor Laboratory Press. 